Alma Mater Studiorum - Università di Bologna DEPARTMENT OF ECONOMICS

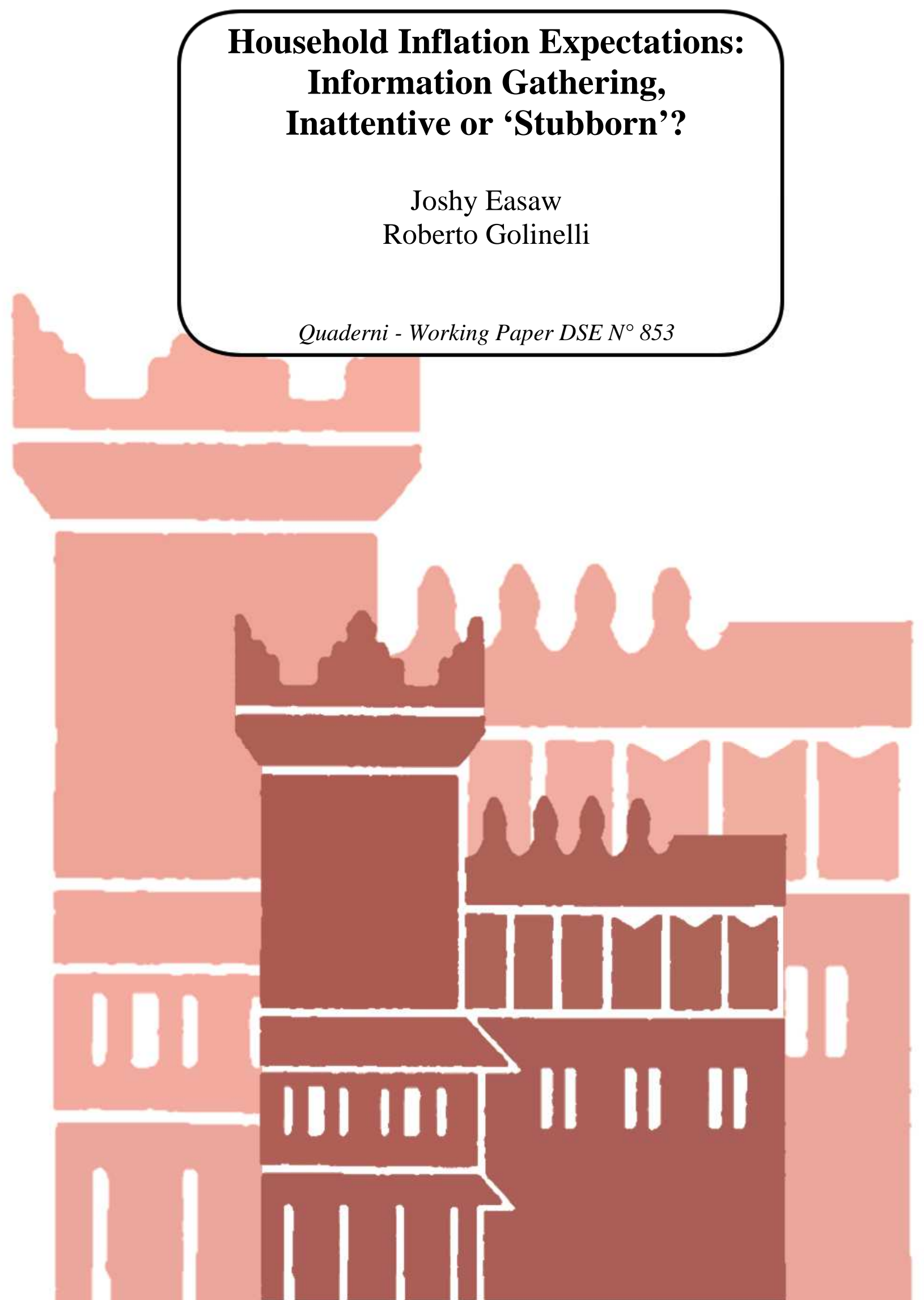




\title{
Household Inflation Expectations: \\ Information Gathering, Inattentive or ‘Stubborn’?
}

Joshy Easaw $^{a}$ and Roberto Golinelli ${ }^{b}$

\begin{abstract}
The purpose of this paper is to investigate the microfoundations of how non-experts' (or general public) form inflation expectations. Using a unique dataset we investigate the range of near rational inflation expectations. An important contribution to understanding how non-experts form their expectations is 'sticky information expectations', specifically the epidemiological model. Our analysis uses an extended version of the epidemiological model. We find that the general public are best depicted as those who are either information gathers or inattentive. In addition, the inattentive general public can be either forward-looking or 'stubborn', that is persistent.
\end{abstract}

JEL Codes: D84, E31

Keywords: household inflation expectations, 'sticky information expectations', forward-looking or 'stubborn'.

\section{$9^{\text {th }}$ January 2012}

${ }^{a}$ School of Business and Economics, University of Swansea, Singleton Park, Swansea, SA2 8PP, United Kingdom, E-mail:J.Easaw@swansea.ac.uk

${ }^{b}$ Department of Economics, University of Bologna, Strada Maggiore, 45, 40125 Bologna, Italy, E-mail: roberto.golinelli@unibo.it 


\section{I: Introduction:}

While the inflation expectations of non-experts, especially that of the general public, form a crucial part of price and wage-setting behavior and macroeconomic models, understanding how they form their expectations is less well understood. Nevertheless, increasingly there is a general consensus that agents' expectations are less than rational. For example, the discussion in Mankiw et al (2004) states clearly that "there is a large middle ground between adaptive and hyperrational expectations, and that their paper is an attempt to explore one possible alternative” (p. 270). In an earlier study, Roberts (1997) had concluded that inflation expectations are less than perfectly rational. In a later paper Roberts (1998) presented inflation expectation, specified as a partial adjustment model, which was termed of 'stubborn' expectations. The expressed intention of the present paper is to explore the range of near rational household expectations using a unique dataset.

An important recent theory explaining how non-experts form their expectations is 'rational inattentive behavior'. Reis (2006a and 2006b) argue that both consumers and producers update their information set sporadically. Producers do not continuously update their production plans but choose a price for their output and an optimal time at which to be inattentive, that is they receive no news about the economy until it is time to plan again. Similarly, time constrained consumers optimize their utility and undertake consumption decisions infrequently. The slow diffusion of information among the population is due to the costs of acquiring information as well as the costs of reoptimization, resulting in the 'sticky-information expectations'. Based on the notion of 'stickyinformation expectations' (or rational inattentive behavior), Carroll (2003 and 2006) provide specific microfoundations of how households form their macroeconomic expectations referring to it as 'epidemiological expectations'.

Importantly, the models concur that the non-experts remain forward-looking even in the face of imperfect information. In periods they are able to receive current news or information, and in the case of epidemiological expectations these are the professional forecasts, they are able to form their expectations rationally. In other periods, they have to rely on old news but, nevertheless, 
remain forward-looking. Carroll (2003) through a number of crucial assumptions painstakingly shows that the inattentive households remain forward-looking; even though the ensuing empirical analysis uses lagged one-year ahead forecasts to proxy the forward-looking inattentive household expectations.

In the current paper we present a model which extends the epidemiological expectations model, focusing on the nature of inattentive agents. Similar to the rational inattentive literature, non-expert agents are divided into those that are either 'information gathers' or 'inattentive'. The 'inattentive' agents are further separated into those that are either 'forward-looking' or simply ‘stubborn’. Following Roberts (1998), the term ‘stubborn’ expectation is used to depict agents whose expectations are persistent. 'Information gathers' update their expectations by absorbing the inflation expectations of professional forecasters. We also consider those households that update expectations based on recently available actual inflation rates.

The next section re-states the epidemiological model relaxing the crucial assumptions made in Carroll (2003) while also adapting it to the available dataset. Crucially, we also extend the epidemiological model to allow the inattentive households to be either forward-looking or stubborn. Section III discusses the survey-based dataset and undertakes the empirical investigations and, finally, the concluding remarks are drawn. In brief, we conclude that approximately sixty percent of the general public are inattentive and of whom fifty percent are found to be 'stubborn'. This has direct implications for actual inflation dynamics, especially the 'sticky-information' inflation.

\section{II: The Model:}

Consider the basic premise of the epidemiological version of 'sticky information expectations' as expressed in Carroll (2003) as follows:

$$
M_{t}\left[\pi_{t+1}\right]=\lambda N_{t}\left[\pi_{t+1}\right]+(1-\lambda)\left\{\lambda N_{t-1}\left[\pi_{t+1}\right]+(1-\lambda)\left(\lambda N_{t-2}\left[\pi_{t+1}\right]+\ldots\right\}\right.
$$


where $M_{t}\left[\pi_{t+1}\right]$ denotes households' inflation forecasts for $t+1$ made in $t$, and $N_{t}\left[\pi_{t+1}\right]$ are the corresponding professional forecasts as they are reported by news media in $t$. A proportion of households (or population) $(\lambda)$ are information-gathers and observe the current newspapers' forecast of inflation, which report the professional forecasts. The remaining households $(1-\lambda)$ are inattentive, but retain or follow the previous period's two-period ahead forecasts. Indeed, inattentive households use a combination of multi-period ahead forecasts made in the past for the period $t+1$ when forming their current inflation forecasts. So, while the inattentive households have to rely on previous forecasts due to a lack of current information, they are, most importantly, still forwardlooking as suggested by their use of two-period and multi-period ahead forecasts. When forecasts are made in each quarter, the quarterly one-year ahead forecasts are represented as:

$$
M_{t}\left[\pi_{t, t+4}\right]=\lambda N_{t}\left[\pi_{t, t+4}\right]+(1-\lambda) M_{t-1}\left[\pi_{t, t+4}\right]
$$

where $M_{t}\left[\pi_{t, t+4}\right]$ denotes households' inflation forecasts made in $t$ for the quarters from $t$ to $t+4$ (i.e. over one year since quarter $t), N_{t}\left[\pi_{t, t+4}\right]$ are the corresponding professional forecasts as published via the news media, and $M_{t-1}\left[\pi_{t, t+4}\right]$ are the inattentive households' forecasts made in the previous quarter $(t-1)$ over the same horizon (i.e. from $t$ to $t+4$ ).

At this point, Carroll (2003) makes a crucial assumption: permanent innovation to the fundamental rate of inflation $(\eta)$ is unforecastable beyond the next quarter:

$$
F_{t}\left[\eta_{t+n+1}\right]=0 \quad \forall n>0
$$

Under assumption (3) inattentive households inflation forecast depend only on the information set available in the period when the forecast is made and not on its horizon, provided that the number of quarters to be predicted is the same. Therefore, any forecast $(F)$ made in $t-1$ for any future period of four quarters (i.e. over the one year) over any horizon is the same, i.e.: $F_{t-1}\left[\pi_{t-1, t+3}\right]=$ $F_{t-1}\left[\pi_{t, t+4}\right]=F_{t-1}\left[\pi_{t+1, t+5}\right]=F_{t-1}\left[\pi_{t+2, t+6}\right]=F_{t-1}\left[\pi_{t+3, t+7}\right]$ and so on. Consequently, equation (2) is denoted as: 


$$
M_{t}\left[\pi_{t, t+4}\right]=\lambda N_{t}\left[\pi_{t, t+4}\right]+(1-\lambda) M_{t-1}\left[\pi_{t-1, t+3}\right]
$$

where $M_{t-1}\left[\pi_{t-1, t+3}\right]$ is the one-year ahead forecast formed in $t-1$, that is the lagged dependent variable. Based on this crucial assumption, the inattentive household forecasts, though stubborn or persistent, are consistent with forward-looking behavior.

In the present dataset, households are asked not only to make a one-year ahead forecast on a quarterly basis, where they forecast inflation over the forthcoming year (i.e. the next four quarters ahead), but they are also asked to make two-year ahead forecasts for the subsequent year (i.e. between four and eight quarters ahead). Therefore, the epidemiological model can be alternatively stated as follows:

$$
\begin{aligned}
& M_{t}\left[\pi_{t, t+4}\right]=\lambda F_{t}\left[\pi_{t, t+4}\right]+(1-\lambda)\left\{\lambda F_{t-1}\left[\pi_{t+3, t+7}\right]+(1-\lambda)(\ldots . .)\right\} \\
& M_{t}\left[\pi_{t, t+4}\right]=\lambda S_{t}\left[\pi_{t, t+4}\right]+(1-\lambda) M_{t-1}\left[\pi_{t+3, t+7}\right]
\end{aligned}
$$

where $S_{t}\left[\pi_{t, t+4}\right]=N_{t}\left[\pi_{t, t+4}\right]$ denotes the mean of the surveyed professional forecasts which are reported by the news media. Now the rational households will form their year ahead forecasts based on current news, and the inattentive ones will form their forecasts based on their previous period's two-year ahead forecasts; therefore, both rational and inattentive households are forward-looking.

In order to ensure that inattentive agents display just forward-looking behavior, we need to relax assumption (3) and allow the permanent innovation to be forecastable beyond the forthcoming year or next four quarters, i.e. $F_{t-1}\left[\eta_{t+3, t+7}\right] \neq 0$, and: $F_{t-1}\left[\pi_{t+3, t+7}\right]=F_{t-1}\left[\pi_{t-1, t+3}\right]+F_{t-1}\left[\eta_{t+3, t+7}\right]$. Of course, if assumption (3) is valid, models (4) and (5) tend to coincide, as $M_{t-1}\left[\pi_{t, t+4}\right] \approx M_{t-1}\left[\pi_{t+3, t+7}\right]{ }^{1}$ If it is not valid, an unresolved question is: what does the inattentive households expectations represent in Carroll's epidemiological model?

\footnotetext{
${ }^{1}$ Given that underlying forecasts made in $t-1$ are the same (i.e. $F_{t-1}\left[\pi_{t, t+4}\right]=F_{t-1}\left[\pi_{t+3, t+7}\right]$ ), also their observable components might be very similar.
} 
A possible explanation is the inattentive households could be distinguished between those that display either purely forward-looking or stubborn (or persistent) behavior. Forward-looking households use their two (or multi)-year ahead forecasts from the previous period. Those inattentive households who rely on their lagged one-year ahead forecasts are simply stubborn, as defined in Roberts (1998): their inflation expectations 'are "stubborn” because adjust gradually to their “rational” value.' (pp. 5). Also, arguing that an interpretation of the stubborn expectations is the habit persistence in inflation expectations. Therefore, the inattentive agents in model (5) can be extended as follows:

$$
M_{t}\left[\pi_{t, t+4}\right]=\lambda S_{t}\left[\pi_{t, t+4}\right]+(1-\lambda)\left(\varphi M_{t-1}\left[\pi_{t-1, t+3}\right]+(1-\varphi) M_{t-1}\left[\pi_{t+3, t+7}\right]\right)
$$

where $\varphi$ is the proportion of inattentive households (or population) that are stubborn, and the remainder $(1-\varphi)$ are forward-looking. The remainder of the paper empirically investigates the issues raised in this section.

\section{III: Empirical Analysis}

The data used in the empirical analysis are quarterly data compiled by Barclays Basix based on surveys of various sections of the UK population about their expected inflation rate over the period 1986Q4-2005Q1. Since 2005Q1 they abandoned collecting the relevant information at a disaggregate level and just focused on the 'general public'. The available dataset reports the mean forecasts for both the professional forecasts, or business economist (be), and general public ( $g p$ ) but not the individual forecasts.

The professionals surveyed are simply asked their expectations of RPI:

"Can you tell me what you expect the rate of inflation to be over the next twelve months?"

The members of the general public, on the other hand, are specifically asked²:

\footnotetext{
${ }^{2}$ Clearly, the surveyed members of the general public are given specific choice for their inflation forecasts and, therefore, lead by the surveyor. Interestingly, if the general public learns from professional forecasters via the news media as found in Carroll (2003 and 2006), such a format would only serve to jog their memory.
} 
"From this list, can you tell me what you expect the rate of inflation to be over the next 12 months? 'below zero', 'about 1\%', 'about 2\%', ...,'about 10\%', 'above 10\%', 'don't know'."

These represent the one- year ahead forecasts of both professionals $\left(S_{t}\left[\pi_{t, t+4}\right]\right)$ and households $\left(M_{t}\left[\pi_{t, t+4}\right]\right)$. Both agents are then asked:

Q2. And how about the following twelve months?

And this represents the respective two-year ahead forecasts $\left(S_{t}\left[\pi_{t+4, t+8}\right]\right.$ and $\left.M_{t}\left[\pi_{t+4, t+8}\right]\right)$.

For the present purpose, the Barclays Basix survey has two key advantages. Firstly, the survey includes both the professional and general public forecast of inflation rates. Other studies have had to rely on more than one source for the relevant information. For example studies for the US use separate surveys (with different timing of data collection) from Michigan SRC for the general public and SPF for the professional's forecasts. Secondly - and more importantly - the Barclays Basix survey asks agents to simultaneously provide both a one-year and two-year ahead forecasts for inflation.

If assumption (3) is valid, we expect that the difference between households two- and oneyear ahead forecasts of inflation $\left(M_{t}\left[\pi_{t+4, t+8}\right]-M_{t}\left[\pi_{t, t+4}\right]\right)$ to be close to zero. Figure 1 plots the forecasts difference for the general public $(g p)$ and business economists (be), i.e. $\left.S_{t}\left[\pi_{t+4, t+8}\right]-S_{t}\left[\pi_{t, t+4}\right]\right)^{3}$

Figure 1 here

Both differences are persistently non-zero and are also characterized by large swings, suggesting the presence of near unit-root data generation processes. Visual inspection of Figure 1 is corroborated

\footnotetext{
${ }^{3}$ The zero-horizontal line visualises what would be the realisation of Carroll's assumption on the unforecastability over horizons larger than one-quarter ahead, while the two vertical lines split the entire sample period - from 1986q4 to 2005q1 - in three subsamples corresponding to important events: (1) the period up to 1992q3 that corresponds to the UK's participation in the ERM regime, characterized by large inflation volatility; (2) the period from 1992q4 to 1997q3 of stable inflation with inflation targeting (with interest rate decisions made by the Chancellor of the Exchequer); and (3) the period since 1997q4 that covers the phase of explicit inflation targeting under an independent Bank of England.
} 
by the univariate statistics reported in Table 1 . The unit-root tests never reject the null of nonstationary levels for both the series.

Table 1 here

The autocorrelation coefficients of levels are always significantly positive suggesting that the forecasts of permanent innovations are largely unrevised from quarter to quarter. Autocorrelation coefficients of the first differences are close to zero and only occasionally significant. In particular, the autocorrelation coefficient for the first difference of $g p$ inflation forecasts is significant only in the short-run (up to four lags); suggesting that $g p$ forecasts of future permanent innovations are similar in consecutive quarterly forecasts. As far as be forecasts are concerned, the difference between two- and one-year ahead inflation forecasts is a random walk process. The evidence indicates clearly that agents can formulate non-zero forecasts for permanent innovations beyond the next period and, in doing so, it invalidates assumption (3)

In order to model the stylized facts outlined in Section II, we modify Carroll (2003 and 2006) epidemiological expectations, i.e. model (2). In the first instances following Lanne et al (2009) and Brazier et al (2008) we include the naive household's rule-of-thumb $\left(\pi_{t}\right)$ :

$$
M_{t}\left[\pi_{t, t+4}\right]=\lambda_{1} S_{t}\left[\pi_{t, t+4}\right]+\lambda_{2} M_{t-1}\left[\pi_{t, t+4}\right]+\lambda_{3} \pi_{t}+\varepsilon_{t}
$$

where $\lambda_{i}, i=1,2$, and 3 denotes the proportion (or share) of the population, respectively: rational (observes professional forecasts contemporaneously $\left(S_{t}\left[\pi_{t, t+4}\right]\right.$ )); inattentive (uses the last periods two step ahead forecasts $\left(M_{t-1}\left[\pi_{t, t+4}\right]\right)$ ); and naive (forecasts inflation using the most recently known rate $\pi_{t}$, i.e. the growth rate of prices in the first month of quarter $t$ with respect to the corresponding month of the previous year). In model (7), the explanatory variable $M_{t-1}\left[\pi_{t, t+4}\right]$ is not observable. In the present case, due to the availability of the $g p$ 's two-years ahead forecast, we assume that $M_{t-1}\left[\pi_{t, t+4}\right]=M_{t-1}\left[\pi_{t+3, t+7}\right]$, and obtain the following specification: 


$$
M_{t}\left[\pi_{t, t+4}\right]=\lambda_{1} S_{t}\left[\pi_{t, t+4}\right]+\lambda_{2} M_{t-1}\left[\pi_{t+3, t+7}\right]+\lambda_{3} \pi_{t}+u_{t}
$$

where $\lambda_{2}$ is the proportion of forward-looking inattentive households who use their two-year ahead prediction made in $t-1, M_{t-1}\left[\pi_{t+3, t+7}\right]$, and $u_{t}$ is the error term.

Figure 2 plots the four variables found in model (8). There is evidence of non-stationarity and possibly non constant variability over time (detailed tests are available upon request).

Figure 2 here

The respective columns in Table 2 report the results of alternative estimators which are consistent with stochastic trends and possible autoregressive conditional heteroschedasticity.

\section{Table 2 here}

The main results may be summarized as follows. All the estimated relationships are cointegrated. The sum of the rational, naïve and inattentive households' shares are never significantly different from one, while intercepts are never significant. Approximately $30 \%$ of the general public form their expectations absorbing the professionals' forecasts perfectly, while over half the general public are inattentive and the remaining are naïve 'rule-of-thumbers'. The business economist oneyear ahead forecast is weakly exogenous (see CVAR column) and, therefore, does not have to be simultaneously modeled with $g p$ inflation forecast in the vector error-correction framework. Consequently, the single-equation error-correction specification for $g p$ inflation forecasts conditional on (exogenous) be forecasts and actual inflation is a valid reduction of the multivariate framework (see also Easaw and Golinelli (2010)). The alternative $\lambda_{i}$ coefficient estimates reported in Table 2 proximate each other. They represent the different long-run shares of the various households within a long-run cointegrated relationship. These results support the forward-looking nature of Carroll’s epidemiological model.

As assumption (3) in Carroll (2003) is not fulfilled (as indicated by our results above), we now consider the modified new specification (8). This specification $\left(M_{t-1}\left[\pi_{t, t+4}\right] \approx M_{t-1}\left[\pi_{t+3, t+7}\right]\right)$ is a 
better measure of the unobservable forward-looking regressor than that suggested by Carroll $\left(M_{t-1}\left[\pi_{t, t+4}\right] \approx M_{t-1}\left[\pi_{t-1, t+3}\right]\right)$ - at least the forecast horizon is consistent with forward-looking behavior.

We argued in preceding section that inattentive households could be distinguished between those that are forward-looking $((1-\varphi))$, while updating their expectations using their two-years ahead expectations, and those that are simply stubborn $(\varphi)$ :

$$
M_{t-1}\left[\pi_{t, t+4}\right]=\varphi M_{t-1}\left[\pi_{t-1, t+3}\right]+(1-\varphi) M_{t-1}\left[\pi_{t+3, t+7}\right]
$$

By substituting model (9) into (7) we obtain the general estimable formulation:

$$
M_{t}\left[\pi_{t, t+4}\right]=\lambda_{1} S_{t}\left[\pi_{t, t+4}\right]+\lambda_{2}\left\{\varphi M_{t-1}\left[\pi_{t-1, t+3}\right]+(1-\varphi) M_{t-1}\left[\pi_{t+3, t+7}\right]\right\}+\lambda_{3} \pi_{t}+\varepsilon_{t}
$$

The above specification nests both the original Carroll (2003) model and modified model (8). Therefore, we can test which model better approximates the data. If the null hypothesis $\varphi=0$ is not rejected, the best way to measure inattentive people expectations is to use lags of the two-years ahead expected inflation, as suggested in model (8). While under the alternative $\varphi>0$ there is at least a segment of the inattentive population who are "stubborn".

The estimates of model (10) are reported in Table 3 below. Column (1) reports the estimates of model (10) where $\varphi$ parameter is ex ante restricted to be zero. This enables us to use the results in the first column as a benchmark for the unrestricted estimates of model (10) reported in remaining five columns. The upper panel of Table 3 reports estimates which allow for conditional heteoskedastic GARCH errors, and the lower panel estimates are obtained from a Cointegrated VAR (CVAR) model. These results are also robust using other estimators (i.e. OLS and FM-OLS) but, due to brevity, are not reported here and are available upon request.

\section{Table 3 here}

Despite restricting $\varphi=0$, the estimated results for model (10) mimics model (8). The estimates outlined in the upper and lower part of the first column in Table 3 differ only slightly to the 
corresponding results reported for model (8) in the first (GARCH) and last (CVAR) columns of Table 2. All the estimates reported in Table 3 restrict the intercept to zero, as it was never significant in Table 2. The proximity of the estimates in Table 2 with those in the first column of Table 3 suggests the irrelevance of the intercept in our models.

In all cases the GARCH estimated residuals' diagnostics (reported in the upper panel) never rejects the null of white noise errors, while CVAR estimates statistics in the lower panel (more appropriate for non-stationary variables) always find a cointegration rank of one. We also find weak exogeneity for the respective professionals’ forecast (this point will be elaborated further below). The second column in Table 3 outlines the results when the restriction $\varphi=0$ is relaxed. The estimated $\varphi$ is between $0.43-0.46$ and is also always significantly different to both zero and one. This result indicates categorically that the combination of the two alternative measures of inattentive inflation forecasts better explains the general public's inflation expectations than that suggested in Carroll (2003), and in model (8) ${ }^{4}$. More interestingly, in model (10) the share of information gathers $\left(\lambda_{1}\right)$ remains more or less the same as that in model (8) - that is around 30-35\% depending on the estimation method, while $\lambda_{2}$ increases (from $45-55 \%$ to $58-62 \%$ ) and $\lambda_{3}$ decreases (from $22-23 \%$ to $15-16 \%$ ). This suggests clearly that a better depiction or specification of the inattentive general public increases their estimated share at the expenses of that of the naive households.

Both the first and the second column in Table 3 are labeled as be because we proxy professional forecasts with those of the business economists group (as in Table 2). However, it could be argued that the be forecasts may be somewhat different to that reported in the news. For instances, in the literature when using US data, the expectations reported in the news are proxies of the inflation expectations recorded in the Survey of Professional Forecasters (SPF), while

\footnotetext{
${ }^{4}$ The finding of 'stubbornness' in inflation expectations is consistent with other recent analysis. For instances, Blanchflower and Kelly (2008) using survey data and Goecke et al (2011) and Pfajfar and Zakelj (2009) using an experimental approach find that households' expectations are stubborn.
} 
Livingston Survey (LS) is another option. In addition to the expectations of the business economists (be), the Barclays Basix survey for the UK also reports the expected inflation rates for three other groups of professional forecasters: academic economists $(a e)$, financial directors $(f d)$, and trade unionists (tu) (see Kelly (2008) for a detailed discussion). Hence, we also estimate model (10) using the other groups of professional forecasts as proxies for expectations reported in the news media. The results are found in columns three to five in Table 3. We obtain qualitatively similar results as those estimated for be. Our results are robust to alternative definitions of news media reported forecasts. Finally, studies using the SPF and LS tend to use the average of the individual response for different groups of experts and economists. So for consistency, in the last column in Table 3 (labeled "Average"), we report the average for the four groups of professionals' forecasts reported in the Barclays Basix dataset. Once again, results confirm all the findings using the be group. Approximately a third of the general public form their expectations absorbing the professionals' forecasts perfectly, while about $60 \%$ of the general public are inattentive - of whom about half are 'stubborn' and, finally, about $10 \%$ are naïve 'rule-of-thumbers'.

Finally, and on a minor note, the GARCH estimates reported in the upper panel of Table 3 allows us to quantify the temporal pattern of the time-varying variance of the random shocks $\varepsilon_{t}$ in model (10). ${ }^{5}$ Figure 3 below reports the temporal pattern of the conditional variance of the shocks to general public inflation expectations corresponding to the four alternative groups of professional forecasters in Table 3 and to their average. The results confirm the high variability of the random shocks to households' expectations - characterized by UK's participation in the Exchange Rate mechanism (ERM) regime up to 1992. This reduces considerably since the beginning of the inflation targeting period. Inflation targeting began soon after UK exited the ERM and the Bank of England was made operationally independent in 1997.

\section{Figure 3 here}

\footnotetext{
${ }^{5}$ The GARCH(1,1) estimator of model (10) parameters assumes that the random shocks $\varepsilon_{t}$ have a variance $\sigma_{t}^{2}$ modeled as: $\sigma_{t}^{2}=\omega_{0}+\omega_{1} \varepsilon_{t-1}^{2}+\omega_{2} \sigma_{t-1}^{2}$.
} 


\section{Concluding Remarks}

This paper investigates an important aspect of macroeconomic expectations - notably the microfoundations of how non-experts' (or general public) form inflation expectations. Using a unique dataset we investigate the range of near rational inflation expectations. We use an extended version of an important recent contribution to the literature: the epidemiological version of 'sticky information expectations' or 'rational inattentive' behavior. We are now able to relax some of the crucial assumptions made in Carroll (2003 and 2006) necessitated by data limitations. Consequently, we are able to disentangle more clearly the different household behavior as they form their inflation expectations and their respective proportion share of the population.

The epidemiological model divides the population into households that are rational, as they observe professional forecasts contemporaneously via the news media, and inattentive households have to rely on their past expectations which are, nevertheless, forward-looking. Our empirical analysis highlights three key issues. In the first instances, households are able to form two-period (or two-year) ahead forecasts for permanent innovations. Secondly, the general public who are 'information gathers' tend to either absorb the professionals' inflation forecasts or form their inflation expectations anchoring on actual current inflation rates. Finally, and most importantly, inattentive households can be distinguished between those that are forward-looking and those that are stubborn, as they rely on lagged expectations that are just one-year ahead. We can conclude that approximately sixty percent of the general public are inattentive and of whom fifty percent are found to be 'stubborn'.

In view of the present analysis, an important question is: how does it affect the 'stickyinformation Phillips curve' (Mankiw and Reis (2002))? Does one need to account for the proportion of 'inattentive' general public or just those that are stubborn? These issues, however, are beyond the scope of the present paper. 


\section{References}

Bollerslev, T., R. F. Engle and D. B. Nelson (1994), “ARCH Models” in R. F. Engle and D. L. McFadden (eds.), Handbook of Econometrics, Vol. 4, Ch. 49, Elsevier.

Blanchflower, D. G. and R. Kelly (2008), "Macroeconomic Literacy, Numeracy and the Implications for Monetary Policy", Bank of England Speech, April 29th.

Brazier, A., R. Harrison, M. King and T.Yates., (2008), "The Danger of Inflation Expectations of Macroeconomic Stability: Heuristic Switching in an Overlapping-Generations Monetary Model”. International Journal of Central Banking Vol. 4 (2), pp. 219-254.

Carroll, C. D. (2003), Macroeconomic Expectations of Households and Professional Forecasters”, The Quarterly Journal of Economics, February, 269-298.

(2006), “The Epidemiology of Macroeconomic Expectations” in L. Blume and S. Durlauf, (eds.), The Economy as an Evolving Complex System, III, Oxford University Press.

Dickey, D. A. and W. A. Fuller (1979). "Distribution of the Estimators for Autoregressive Time Series with a Unit Root", Journal of the American Statistical Association, 74, 427-431.

Easaw, J. and R. Golinelli (2010), "Household Forming Inflation Expectations: Active and Passive Absorption Rates”, B.E. Journal of Macroeconomics (contributions), 10(1), article 35.

Engle, R. F. and C. W. J. Granger (1987). "Co-integration and Error Correction: Representation, Estimation, and Testing”, Econometrica, 55, 251-276.

Ivanov, V. and L. Kilian (2005), “A Practitioner’s Guide to Lag Order Selection for VAR Impulse Response Analysis”, Study in Nonlinear Dynamics \& Econometrics, 9(1), Article 2.

Johansen, S. (1992), “Cointegration in Partial Systems and the Efficiency of Single-Equation Analysis”, Journal of Econometrics, 52, 389-402.

(1995). Likelihood-based Inference in Cointegrated Vector Autoregressive Models, Oxford University Press.

Goecke, H., W.J. Luham and M.W.M. Roos (2011), "Rational Inattentiveness in the Lab: the Effect of Information Costs on Forecasting", TU Dortmund manuscript.

Kelly, R., (2008), "The causal relationship between inflation and inflation expectations in the United Kingdom”, External MPC Unit, Bank of England, Discussion Paper, 24.

Lanne, M. A, Luoma, A. and Luoto, J, (2009), “A Naïve Sticky Information Model of Households’ Inflation Expectations”, Journal of Economics Dynamics and Control, 33, 1332-1344.

MacKinnon, J. G., A. A. Haug, and L. Michelis (1999), "Numerical Distribution Functions of Likelihood Ratio Tests for Cointegration”, Journal of Applied Econometrics, 14, 563-577. 
Mankiw, N. G., R. Reis and J. Wolfers (2004), “Disagreement about Inflation Expectations”, NBER Macroeconomics Annual 2003, 18, 209-270.

Mankiw, N. G. and R. Reis (2002), "Sticky Information Versus Sticky Prices: A Proposal to Replace the New Keynesian Phillips Curve”, Quarterly Journal of Economics, 117, 12951328.

Ng, S. and P. Perron (1995), "Unit Root Test in ARIMA Models With Data Dependent Methods for the Selection of the Truncation Lag”, Journal of the American Statistical Association, 90, 268-281.

Phillips, P. C. B. and B. E. Hansen (1990), "Statistical Inference in Instrumental Variables Regression with I(1) Processes”, Review of Economics Studies, 57, 99-125.

Pfajfar, D. and B. Zakelj (2009), "Experimental Evidence on Inflation Expectation Formation", Tilburg University Discussion Paper, No. 2009-07.

Reis, R. (2006a), “Inattentive Consumers”, Journal of Monetary Economics, 53, pp. 1761-1800. (2006b), "Inattentive Producers”, Review of Economics Studies, 73, 793-821.

Roberts, J., (1997), “Is Inflation Sticky?” Journal of Monetary Economics, 39, pp. 173-196.

Roberts, J., (1998), "Inflation Expectations and the Transmission of Monetary Policy", Federal Reserve Board FEDS working paper, No. 1998-43. 
Table 1 - Univariate analysis of the difference between inflation forecasts ${ }^{a}$

General public

Business economist

$g p$

be

Mean

0.39

0.11

Median

0.50

0.20

Maximum

0.90

0.90

Minimum

$-0.90$

$-1.20$

Standard Deviation

0.40

0.50

Skewness

$-1.70$

Kurtosis

5.04

Jarque-Bera, p-value

0.0000

3.72

ADF statistic $^{b}$

$-2.10$

0.0014

$\mathrm{p}$-value

0.2453

$-2.55$

0.1084

Autocorrelation ${ }^{c}$

- Levels, lag:

1
2
3
4
8
12

0.901

0.839

0.757

0.684

0.636

0.576

0.560

0.440

0.209

$-0.004$

12

$-0.054$

$-0.218$

- First differences, lag:

$\begin{array}{crr}1 & 0.267 & -0.001 \\ 2 & -0.069 & -0.153 \\ 3 & -0.244 & 0.107 \\ 4 & -0.272 & -0.060 \\ 8 & 0.015 & -0.079 \\ 12 & 0.053 & 0.056\end{array}$

$\left({ }^{a}\right)$ Differences are between two- and one-year ahead forecasts.

$\left.{ }^{(}{ }^{b}\right)$ Dickey and Fuller (1979) test with truncation lags set by MAIC (Modified AIC) selection rule of Ng and Perron (2001).

(c) Asymptotic standard error (lag >0): 0.118 . 
Table 2 - Estimation results of model (8) ${ }^{a}$

\begin{tabular}{|c|c|c|c|c|}
\hline & OLS & GARCH & FM-OLS & CVAR \\
\hline$\lambda_{1}$ & $\begin{array}{l}0.3725 \\
0.0651\end{array}$ & $\begin{array}{l}\mathbf{0 . 3 3 9 4} \\
0.0806\end{array}$ & $\begin{array}{l}\mathbf{0 . 2 2 3 7} \\
0.0886\end{array}$ & $\begin{array}{l}\mathbf{0 . 3 2 8 5} \\
0.0607\end{array}$ \\
\hline$\lambda_{2}$ & $\begin{array}{l}\mathbf{0 . 4 3 7 0} \\
0.0891\end{array}$ & $\begin{array}{l}\mathbf{0 . 5 1 4 8} \\
0.1076\end{array}$ & $\begin{array}{l}\mathbf{0 . 6 2 2 0} \\
0.1274\end{array}$ & $\begin{array}{l}\mathbf{0 . 4 7 5 8} \\
0.1196\end{array}$ \\
\hline$\lambda_{3}$ & $\begin{array}{l}\mathbf{0 . 2 4 8 7} \\
0.0474\end{array}$ & $\begin{array}{l}\mathbf{0 . 2 2 6 2} \\
0.0569\end{array}$ & $\begin{array}{l}\mathbf{0 . 2 4 8 5} \\
0.0618\end{array}$ & $\begin{array}{l}\mathbf{0 . 2 3 6 5} \\
0.0441\end{array}$ \\
\hline Intercept & $\begin{array}{l}\mathbf{0 . 3 1 6 5} \\
0.2937\end{array}$ & $\begin{array}{l}\mathbf{0 . 0 7 1 6} \\
0.3545\end{array}$ & $\begin{array}{r}\mathbf{- 0 . 1 1 7 4} \\
0.4045\end{array}$ & $\begin{array}{l}\mathbf{0 . 0 1 1 5} \\
0.1679\end{array}$ \\
\hline$\lambda_{1}+\lambda_{2}+\lambda_{3}$ & $\begin{array}{l}\mathbf{1 . 0 5 8 2} \\
0.0487\end{array}$ & $\begin{array}{l}\mathbf{1 . 0 8 0 5} \\
0.0599\end{array}$ & $\begin{array}{l}\mathbf{1 . 0 9 4 1} \\
0.0639\end{array}$ & $\begin{array}{r}1.0408 \\
-\end{array}$ \\
\hline \multicolumn{5}{|l|}{ Diagnostics tests: } \\
\hline $\begin{array}{l}\text { Cointegration, p-value }{ }^{b, c} \\
\text { Weak exogeneity, p-value }^{d}\end{array}$ & 0.0001 & 0.0001 & 0.0001 & $\begin{array}{l}0.0035 \\
0.9005\end{array}$ \\
\hline Durbin Watson residuals' autocorrelation & 1.48 & 1.57 & 1.70 & 1.93 \\
\hline
\end{tabular}

( $\left.{ }^{\mathrm{a}}\right)$ In bold, parameter estimates and, below, their standard errors. Estimation methods: OLS = Ordinary Least Squares; GARCH = GARCH(1,1), see Bollerslev et al. (1994); FM-OLS = Fully-Modified OLS, see Phillips and Hansen (1990); CVAR = Cointegrated VAR, see Johansen (1992 and 1995).

$\left.{ }^{(}{ }^{b}\right)$ In the first three columns, residual-based Engle and Granger (1997) test (truncation lags of the unit-root test equation are MAIC-selected, see Ng and Perron, 2001). In the fourth column, Johansen's trace rank test in a VAR(1) with constant restricted to lie in the cointegration space and conditional on the most recently known actual inflation in $t$ and $t-1$; the VAR order is selected on the basis of Schwarz Information Criterion, see Ivanov and Kilian (2005). All the following tests for rank $\leq 1$ are never rejected. The p-value of the null hypothesis that rank $=0$ in a VAR(1) model without conditioning inflation series is 0.001 .

(c) MacKinnon et al (1999) p-values.

$\left({ }^{d}\right)$ Test for the weakly exogeneity of business economists' forecast series in making inferences on the cointegrating relationship and the loading parameters, see Johansen (1992 and 1995). The p-value of the weak exogeneity test in a $\operatorname{VAR}(1)$ without conditioning inflation is 0.3935 . 
Table 3 - Estimation results of model (10) ${ }^{a}$

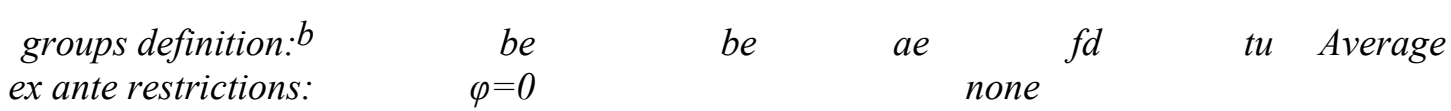

Estimation method: OLS with GARCH $(1,1)$ errors

$\begin{array}{lllllll}\lambda_{1} & \mathbf{0 . 3 3 1 4} & \mathbf{0 . 2 9 7 6} & \mathbf{0 . 3 6 5 0} & \mathbf{0 . 3 4 0 0} & \mathbf{0 . 2 5 2 6} & \mathbf{0 . 3 3 4 6} \\ & 0.0789 & 0.0552 & 0.0623 & 0.0620 & 0.0647 & 0.0628 \\ \lambda_{2} & \mathbf{0 . 5 3 6 5} & \mathbf{0 . 6 2 1 1} & \mathbf{0 . 6 4 4 4} & \mathbf{0 . 6 4 2 2} & \mathbf{0 . 7 1 2 0} & \mathbf{0 . 6 3 6 7} \\ & 0.0358 & 0.0408 & 0.0436 & 0.0440 & 0.0438 & 0.0429 \\ \varphi & & \mathbf{0 . 4 5 6 7} & \mathbf{0 . 4 3 8 8} & \mathbf{0 . 5 4 6 7} & \mathbf{0 . 5 7 6 3} & \mathbf{0 . 4 9 7 5} \\ & & 0.1464 & 0.1653 & 0.1556 & 0.1518 & 0.1588 \\ \lambda_{3} & \mathbf{0 . 2 2 2 1} & \mathbf{0 . 1 6 3 0} & \mathbf{0 . 0 6 5 6} & \mathbf{0 . 0 9 0 6} & \mathbf{0 . 0 6 8 2} & \mathbf{0 . 0 9 8 9} \\ & 0.0389 & 0.0385 & 0.0418 & 0.0433 & 0.0476 & 0.0441 \\ \lambda_{1}+\lambda_{2}+\lambda_{3} & \mathbf{1 . 0 9 0 0} & \mathbf{1 . 0 8 1 7} & \mathbf{1 . 0 7 5 0} & \mathbf{1 . 0 7 2 9} & \mathbf{1 . 0 3 2 9} & \mathbf{1 . 0 7 0 2} \\ & 0.0519 & 0.0452 & 0.0489 & 0.0504 & 0.0517 & 0.0504 \\ \text { Durbin Watson test } & & & & & & \\ \text { Autocorrelation (p-values) } & 1.6031 & 1.7467 & 1.8748 & 1.7289 & 1.7227 & 1.7557 \\ \text { - 1st order } & & & & & & \\ \text { - 4th order } & 0.1000 & 0.3820 & 0.5000 & 0.2120 & 0.4210 & 0.3640 \\ \text { - 8th order } & 0.1050 & 0.7300 & 0.5120 & 0.1910 & 0.2000 & 0.2250 \\ \text { Heteroskedasticity (p-values) } & 0.1890 & 0.7290 & 0.3850 & 0.1020 & 0.1850 & 0.2010 \\ \text { - 1st order } & & & & & & \\ \text { - 4th order } & 0.6000 & 0.3520 & 0.7250 & 0.4060 & 0.2530 & 0.4380 \\ \text { - 8th order } & 0.6690 & 0.2640 & 0.6970 & 0.0770 & 0.2080 & 0.3230 \\ & 0.3210 & 0.2600 & 0.6200 & 0.0580 & 0.4630 & 0.2620\end{array}$

Estimation method: Cointegrated VAR

\begin{tabular}{|c|c|c|c|c|c|c|}
\hline$\lambda_{1}$ & $\begin{array}{l}\mathbf{0 . 3 4 1 9} \\
0.0417\end{array}$ & $\begin{array}{l}\mathbf{0 . 3 8 3 1} \\
0.0879\end{array}$ & $\begin{array}{l}\mathbf{0 . 4 4 0 6} \\
0.0880\end{array}$ & $\begin{array}{l}\mathbf{0 . 4 5 5 1} \\
0.0941\end{array}$ & $\begin{array}{l}\mathbf{0 . 3 8 9 8} \\
0.0757\end{array}$ & $\begin{array}{l}\mathbf{0 . 4 3 5 3} \\
0.0820\end{array}$ \\
\hline$\lambda_{2}$ & $\begin{array}{l}\mathbf{0 . 4 4 7 4} \\
0.1141\end{array}$ & $\begin{array}{l}\mathbf{0 . 5 7 8 1} \\
0.1100\end{array}$ & $\begin{array}{l}\mathbf{0 . 5 6 2 3} \\
0.1016\end{array}$ & $\begin{array}{l}\mathbf{0 . 5 6 4 1} \\
0.1070\end{array}$ & $\begin{array}{l}\mathbf{0 . 5 7 2 7} \\
0.1113\end{array}$ & $\begin{array}{l}\mathbf{0 . 5 5 7 0} \\
0.1049\end{array}$ \\
\hline$\varphi$ & 0.0000 & $\begin{array}{l}\mathbf{0 . 4 3 0 3} \\
0.2051\end{array}$ & $\begin{array}{l}\mathbf{0 . 2 5 5 2} \\
0.0817\end{array}$ & $\begin{array}{l}\mathbf{0 . 4 4 9 2} \\
0.2252\end{array}$ & $\begin{array}{l}\mathbf{0 . 2 9 8 2} \\
0.1120\end{array}$ & $\begin{array}{l}\mathbf{0 . 3 2 2 5} \\
0.1296\end{array}$ \\
\hline$\lambda_{3}$ & $\begin{array}{l}\mathbf{0 . 2 2 8 6} \\
0.0528\end{array}$ & $\begin{array}{l}\mathbf{0 . 1 4 6 9} \\
0.0457\end{array}$ & $\begin{array}{l}\mathbf{0 . 0 8 8 3} \\
0.0458\end{array}$ & $\begin{array}{l}\mathbf{0 . 0 8 0 9} \\
0.0470\end{array}$ & $\begin{array}{l}\mathbf{0 . 0 9 4 7} \\
0.0482\end{array}$ & $\begin{array}{l}\mathbf{0 . 0 9 9 7} \\
0.0464\end{array}$ \\
\hline$\lambda_{1}+\lambda_{2}+\lambda_{3}$ & 1.0179 & 1.1082 & 1.0912 & 1.1001 & 1.0572 & 1.0921 \\
\hline Cointegration rank $=0^{c}$ & 0.0071 & 0.0071 & 0.0035 & 0.0057 & 0.0039 & 0.0063 \\
\hline Cointegration rank $=1 \mathrm{c}$ & 0.8022 & 0.8022 & 0.7645 & 0.6293 & 0.5049 & 0.7836 \\
\hline Weak exogeneity test $d$ & 0.8587 & 0.1731 & 0.2187 & 0.2695 & 0.1200 & 0.1936 \\
\hline
\end{tabular}

$\left({ }^{\mathrm{a}}\right)$ In bold, parameter estimates and, below, their standard errors. Estimation methods: GARCH(1,1), see Bollerslev et al. (1994); Cointegrated VAR, see Johansen (1992 and 1995).

(b) Groups of professional forecasters: business economists (be), academic economists (ae), financial directors $(f d)$, trade unionists $(t u)$. "Average" is the mean of all four previous groups.

( $\left.{ }^{c}\right)$ P-values of Johansen's trace rank test in a VAR(1) without constant and conditional on the most recently known actual inflation in $t$ and $t-1$; the VAR order is selected on the basis of Schwarz Information Criterion, see Ivanov and Kilian (2005).

(d) P-values of the tests for the weakly exogeneity of professionals' forecast series in making inferences on the cointegrating relationship and the loading parameters, see Johansen (1992 and 1995). 
Figure 1 - Difference between two- and one-year ahead inflation forecasts ${ }^{a}$

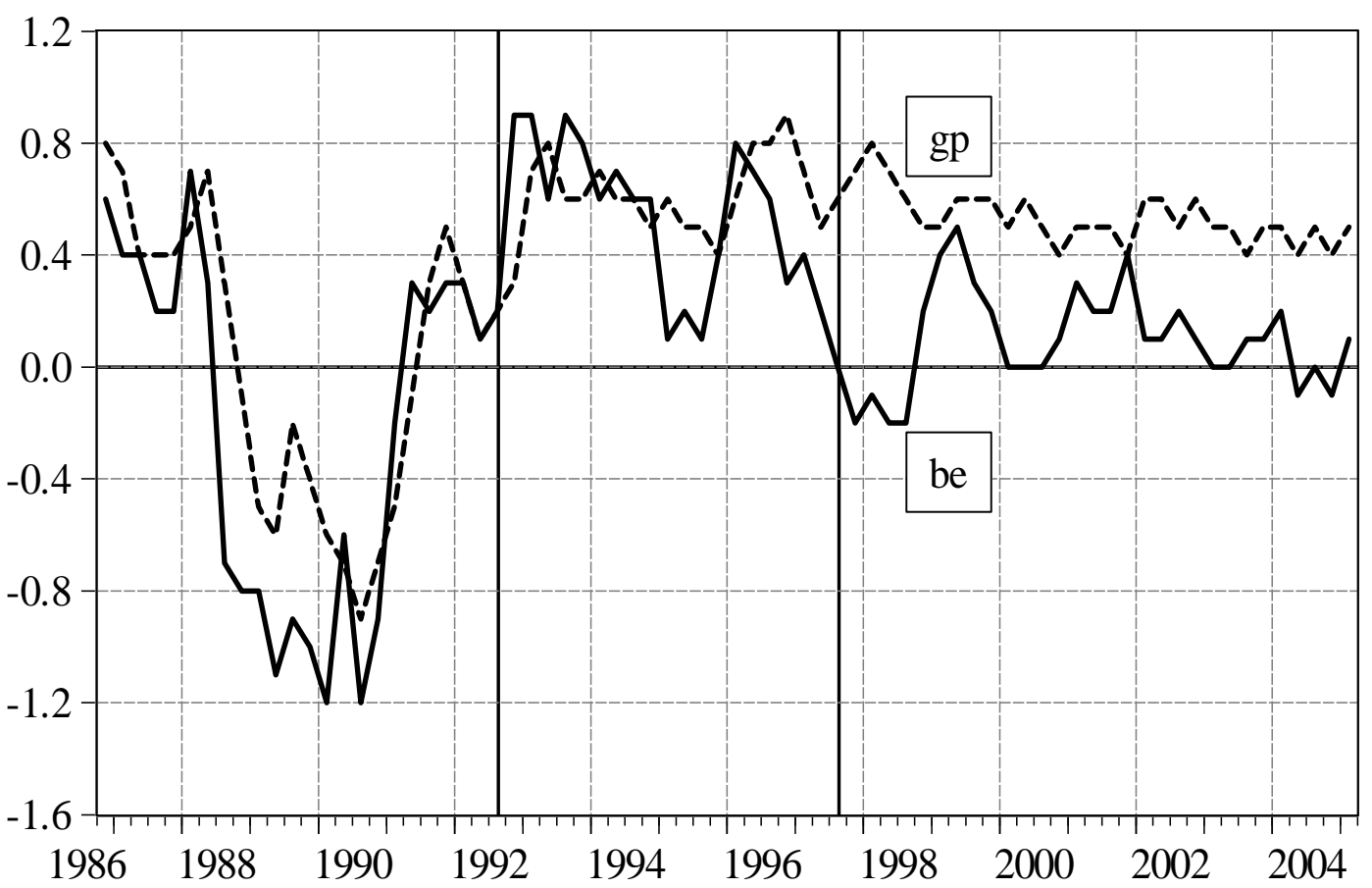

( $\left.{ }^{\mathrm{a}}\right) g p=$ general public; $b e=$ business economists.

Figure 2 - The Forecasts ${ }^{a}$

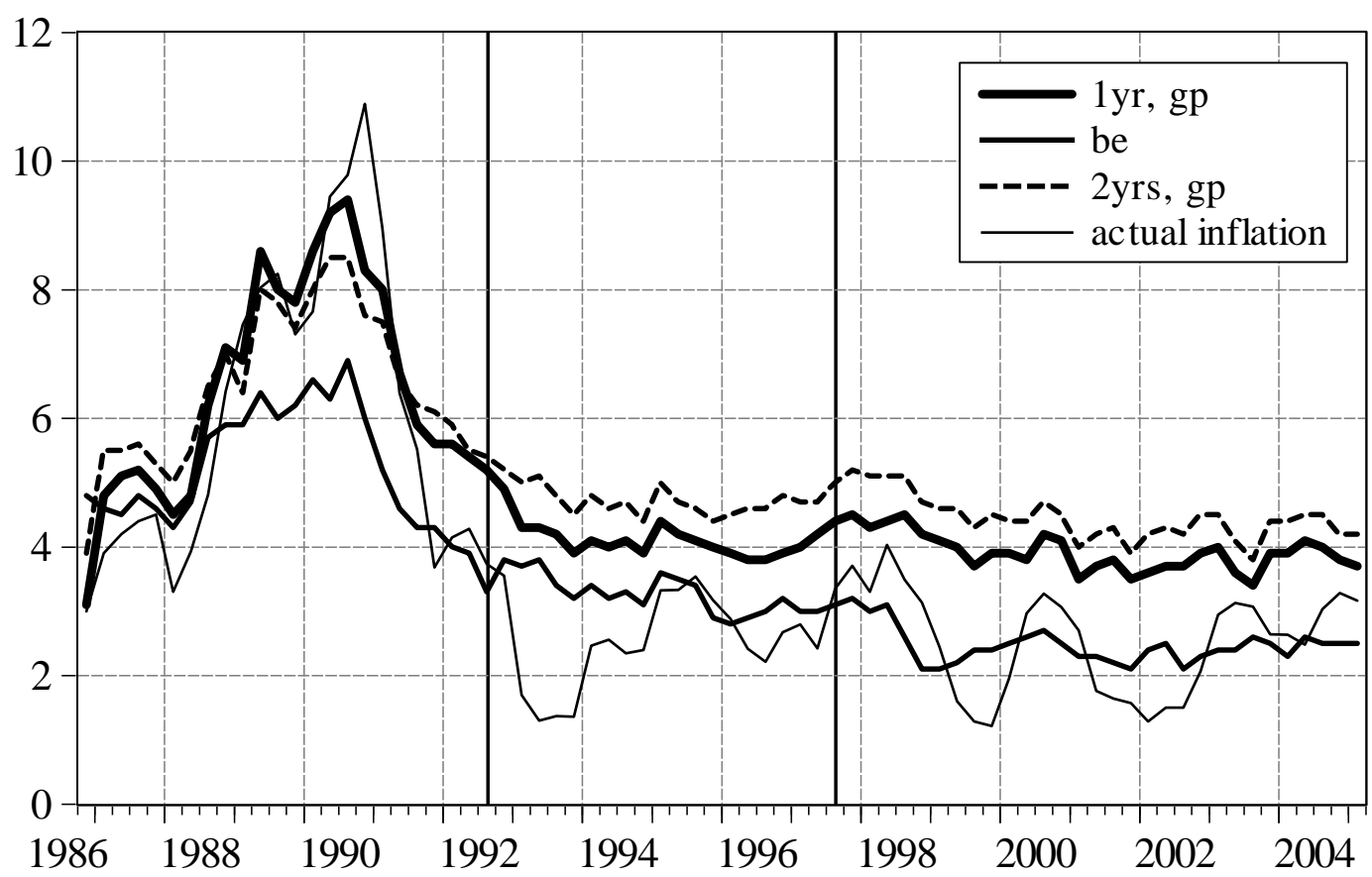

( $\left.{ }^{\mathrm{a}}\right) g p=$ general public; $b e=$ business economists. $1 \mathrm{yr}=$ one-year ahead; $2 \mathrm{yrs}=$ twoyears ahead forecasts. 
Figure 3 - Conditional variance of model (10) GARCH estimates ${ }^{a}$

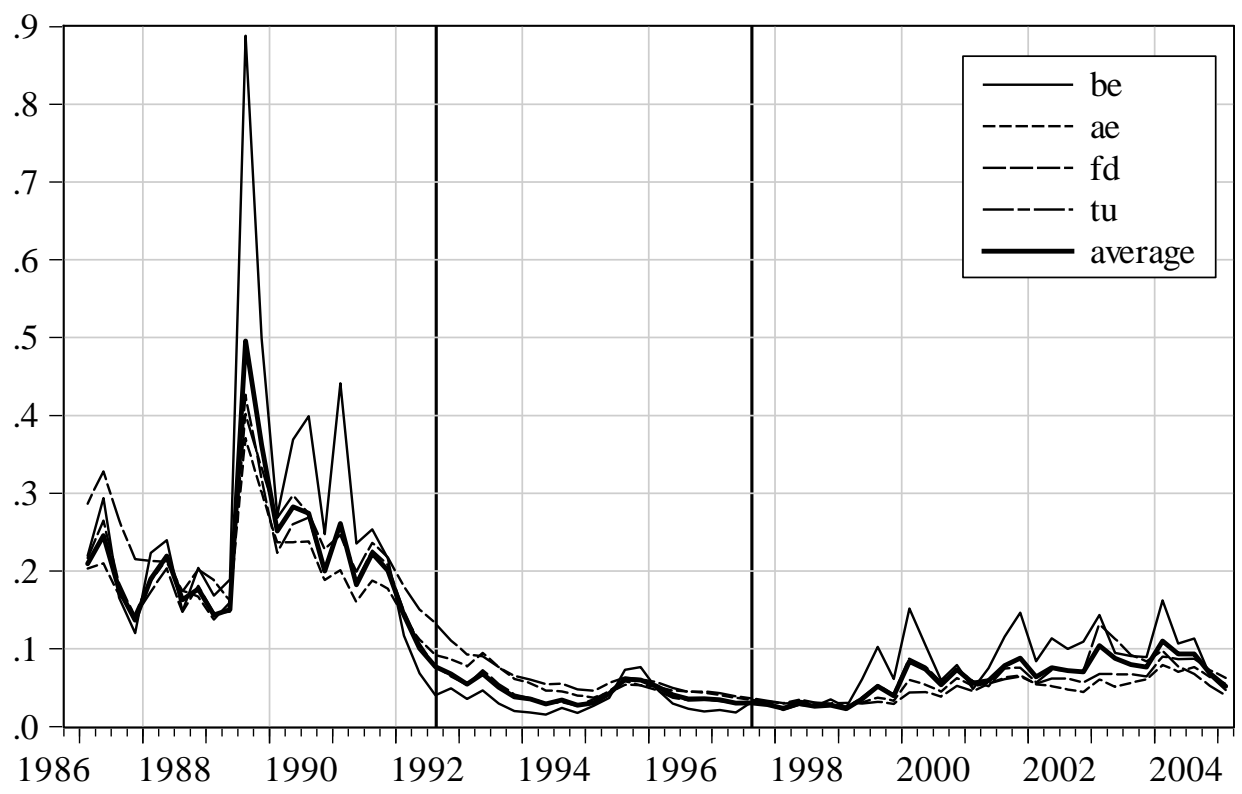

( $\left.{ }^{a}\right)$ Computed by measuring professional forecasts with alternative groups: business economists $(b e)$, academic economists $(a e)$, financial directors $(f d)$, trade unionists $(t u)$. "average" is the mean of all four previous groups. 


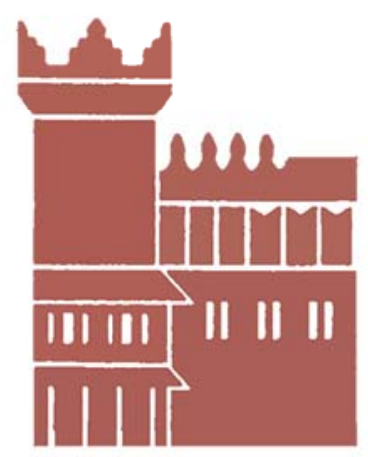

Alma Mater Studiorum - Università di Bologna DEPARTMENT OF ECONOMICS

Strada Maggiore 45

40125 Bologna - Italy

Tel. +39051 2092604

Fax +390512092664

http://www.dse.unibo.it 